\title{
Hemodynamic Stability, Patient Acceptance and Cost of Intravenous Propofol and Inhalational Sevoflurane for Induction of Anaesthesia: A Prospective, Randomized Comparative Study
}

\author{
Kirtibala Dhande ${ }^{1}$, Jitendra Kshirsagar ${ }^{2}$, Ashish Dhande ${ }^{3}$, Narendra Patil ${ }^{4}$, Parvati V Jr. ${ }^{4}$ \\ 1. Anesthesiology, DY Patil Hospital, Navi Mumbai, IND 2. Anesthesiology, Deenanath Mangeshkar Hospital, Pune, \\ IND 3. Urology, DY Patil University - School of Medicine, Navi Mumbai, IND 4. Anesthesiology, DY Patil University - \\ School of Medicine, Navi Mumbai, IND
}

Corresponding author: Kirtibala Dhande, kirtiadhande@gmail.com

\section{Abstract \\ Introduction}

The effects of an anesthetic agent on the hemodynamic stability are of prime importance in patients with compromised hemodynamics. Although comparative studies of sevoflurane and propofol are reported, most of these are aimed to assess maintenance and early postoperative recovery. There are very few studies on hemodynamic changes occurring with these two agents. This study compares the hemodynamic stability, patient acceptance, and cost of intravenous (IV) propofol versus inhalational (IH) sevoflurane for the induction of anesthesia.

\section{Methods}

This prospective, randomized comparative study was conducted among 80 patients with American Society of Anaesthesiologists (ASA) grade-I requiring general anesthesia (GA) for elective surgical procedures. The study was approved by the institutional ethics committee and was conducted as per the principles of the Declaration of Helsinki and Good Clinical Practice (GCP) guidelines. Enrolled patients were randomized to receive either intravenous (IV) propofol $2 \mathrm{mg} / \mathrm{kg}(\mathrm{n}=40)$ or gradual inhalational (IH) induction with sevoflurane $(n=40)$. All patients were maintained with sevoflurane $2 \%$ in $67 \%$ nitrous oxide $\left(\mathrm{N}_{2} \mathrm{O}\right)$ and $\mathrm{O}_{2}$. Hemodynamic parameters like pulse rate and mean arterial pressure (MAP) were monitored every minute up to five minutes. Patients' acceptance was assessed on a 10-item questionnaire, and the cost of anesthesia was assessed based on the anesthetic requirement. The hemodynamic parameters were compared between the two groups using two-way repeat-measures ANOVA. The incidence of hypotension was compared using Fischer's test.

Received 04/06/2020

Review began 04/09/2020 Review ended 04/09/2020 Published 04/16/2020

๑) Copyright 2020

Dhande et al. This is an open access article distributed under the terms of the Creative Commons Attribution License CC-BY 4.0., which permits unrestricted use, distribution, and reproduction in any medium, provided the original author and source are credited.

\section{Results}

The two groups were similar at baseline with respect to the demography and other baseline characteristics. There was greater $(\mathrm{p}<0.05)$ fall in MAP with propofol induction $(28.48 \%)$ compared to sevoflurane $(14.61 \%)$. Greater reduction in pulse rate $(\mathrm{p}<0.05)$ with sevoflurane $(9.18)$ induction was observed compared to propofol (5.28). Patient acceptance for both drugs was similar ( $p>0.05$ ). Although sevoflurane was unpleasant, propofol injection was painful. Ninety percent of patients preferred propofol for repeat anesthesia as against $85 \%$ of patients with sevoflurane. Considering the quantity of anesthetic consumed and the unit cost, propofol was more costly as compared to sevoflurane.

\section{Conclusion}

Sevoflurane maintains better hemodynamic stability compared to propofol, and patient acceptance of both drugs is similar. Induction with sevoflurane was found to be cheaper as compared to propofol induction.

Categories: Anesthesiology, General Surgery

Keywords: sevoflurane, propofol, induction, hypotension, acceptance, pharmacoeconomics, hemodynamic stability

\section{Introduction}

Induction of anesthesia is an important activity in a surgical event, and there are high chances of hemodynamic instability, hypoxia, arrhythmias, and excitatory reflexes. Thus, the induction process should be quick and devoid of any such effects, especially in compromised patients. Although an ideal inducing agent is yet to be seen, the ideal requirements change based on the surgery, pathophysiological condition of the patient, and availability of equipment. An anesthesiologist must wisely select from the available drugs, one that best suits the particular patient. 
Intravenous propofol has been the drug of choice for the induction of anesthesia due to its safety profile, relaxation, depression of upper airway reflexes, and mild bronchodilation [1]. However, it may cause adverse effects such as cardiovascular depression leading to hemodynamic instability, pain on injection, thrombophlebitis, and respiratory depression [2]. Sevoflurane is a halogenated volatile anesthetic agent which is non-irritating to the respiratory tract, has the highest hemodynamic stability, and has bronchodilator activity [3]. Sevoflurane is the best volatile inducing agents with faster induction and rapid recovery [4]. Thus, both propofol and sevoflurane have their own merits and limitations.

Although many investigators have done a comparison of sevoflurane and propofol for their effects on hemodynamic stability, there are no studies which report acceptance of these inducing agents by patients and the cost of inducing agents. We conducted this prospective, randomized study to compare the hemodynamic stability, patient acceptance, and cost of intravenous (IV) propofol versus inhalational (IH) sevoflurane for induction of anesthesia.

\section{Materials And Methods}

\section{Study design and setting}

This randomized, comparative study was carried out after obtaining approval from the institutional ethics committee (IEC). The study was conducted following the principles of the Declaration of Helsinki (World Medical Association) and Good Clinical Practice (GCP) guidelines issued by the Indian Council of Medical Research (ICMR) and the Drugs Controller General of India (DCGI). The study procedures were explained to all patients and informed consent was obtained.

\section{Study subjects}

Patients of either gender, between 20 to 60 years of age, patients of American Society of Anaesthesiologists (ASA) grade I posted for elective surgery and requiring general anesthesia were enrolled after obtaining written informed consent. Patients with allergy to either propofol or sevoflurane or any other drugs were excluded. A total of 80 study eligible patients were randomized to receive IV propofol $(n=40)$ or inhalational sevoflurane $(\mathrm{n}=40)$ for induction of anesthesia. The sample size was not based on any estimations and assumptions, and it was planned to perform posthoc power analysis for the primary outcome of the study.

\section{Randomization and blinding}

Block randomization (block of 40 with two blocks) was done using PC based (Rando V1.0 for MS Windows) predetermined randomization schedule. The randomization was prepared by independent personnel and was concealed in sealed separate envelopes for each study participant. The study team was blinded for the randomization, and allocation was done only after the eligible participant was enrolled and assigned a study serial number. After enrolment, the sealed envelope was opened by the study team members to reveal the treatment allocation for the participant. The study was initiated after randomization was done.

\section{Study procedures}

All patients underwent standard multiparameter monitoring for a pulse, blood pressure, respiration, oxygen saturation $\left(\mathrm{SpO}_{2}\right)$, and electrocardiogram (ECG). All patients were premedicated with IV midazolam 0.02 $\mathrm{mg} / \mathrm{kg}$, and fentanyl $1.5 \mathrm{mcg} / \mathrm{kg}$ [5]. Patients breathed oxygen for one minute through a clear plastic face mask at a flow rate of $5 \mathrm{~L} / \mathrm{min}$ via co-axial Bain circuit as pre-oxygenation. Propofol group patients received IV propofol at a constant rate of $8-10 \mathrm{ml} / \mathrm{min}$ till induction. Sevoflurane group patients were explained about mask induction, and sevoflurane was administered through a transparent face mask starting at $0.5 \%$ and incrementally increased by $0.5 \%$ every $15 \mathrm{sec}$ in $100 \% \mathrm{O}_{2}$ at a total gas flow of $5 \mathrm{~L} / \mathrm{min}$ via co-axial Bain circuit [6]. Induction was confirmed by loss of eyelash reflex. All patients received succinylcholine $2 \mathrm{mg} / \mathrm{kg}$ IV prior to tracheal intubation [7]. All intubations were done by the same investigator. All patients in both groups were maintained with $2 \%$ sevoflurane and $60 \% \mathrm{~N}_{2} \mathrm{O}$ in $\mathrm{O}_{2}$ at $5 \mathrm{~L} /$ minute [8]. An independent observer who was blinded for the treatment recorded the heart rate (HR), systolic blood pressure (SBP), diastolic blood pressure (DBP) at baseline, before midazolam premedication, three minutes after midazolam, pre-induction, post-induction, after intubation and every minute for five minutes after intubation.

\section{Study outcomes}

The primary outcome was the hemodynamic stability assessed by changes in mean arterial pressure (MAP), SBP, DBP, and HR. Secondary outcomes were patient acceptance and the cost of induction. Patient acceptance was recorded on a three-point Likert scale - pleasant, indifferent and unpleasant. Patients were asked whether they would prefer the same anesthetic if required in the future. The cost of induction of anesthesia was calculated based on the market unit price, and the total consumption of anesthetic agents.

\section{Statistical analysis}

The hemodynamic parameters (HR, SBP, DBP, and MAP) were compared between the two groups using the general linear model (GLM) procedure (repeat measures analysis of covariance - ANCOVA) with inducing 


\section{Cureus}

agents as independent variable and age, body weight and gender as covariates. The time of measurements was the baseline, before midazolam, three minutes after midazolam, pre-induction, post-induction, after intubation and every minute for five minutes after intubation. Binary data was compared between two groups using Fischer's chi-square test. All analyses were done using two-sided tests at alpha 0.05 (95\% confidence level), and the cut-off p-value was 0.05 for tests of significance. Statistical analyses were performed using the Statistical Package for Social Sciences, version 17.0 (SPSS Inc, Chicago, Illinois).

\section{Results}

The demographic characteristics of patients in the two groups are shown in Table 1 . Both groups were similar with respect to the demography and baseline data $(\mathrm{p}>0.05)$.

\begin{tabular}{|c|c|c|c|c|c|c|}
\hline & \multicolumn{2}{|c|}{ IV propofol $(n=40)$} & \multicolumn{2}{|c|}{ IH sevoflurane $(n=40)$} & \multicolumn{2}{|l|}{ ANOVA } \\
\hline & Mean & SD & Mean & SD & $\mathrm{F}$ & $\mathrm{p}$ \\
\hline Age (years) & 33.20 & 10.83 & 34.55 & 9.84 & 0.341 & 0.561 \\
\hline Body weight (kg) & 59.30 & 12.08 & 60.75 & 10.37 & 0.332 & 0.566 \\
\hline Heart rate (per min) & 77.63 & 12.88 & 76.10 & 15.39 & 0.231 & 0.632 \\
\hline Systolic blood pressure (mm Hg) & 126.43 & 14.70 & 131.73 & 12.88 & 2.941 & 0.090 \\
\hline Diastolic blood pressure (mm Hg) & 78.98 & 10.74 & 75.90 & 10.40 & 1.692 & 0.197 \\
\hline Mean arterial pressure $(\mathrm{mm} \mathrm{Hg})$ & 94.79 & 11.46 & 94.51 & 8.98 & 0.015 & 0.902 \\
\hline Gender & No. & $\%$ & No. & $\%$ & Chi-square & $\mathrm{p}$ \\
\hline Male & 12 & $30.0 \%$ & 19 & $47.5 \%$ & & \\
\hline Female & 28 & $70.0 \%$ & 21 & $52.5 \%$ & & \\
\hline
\end{tabular}

TABLE 1: Demography and baseline data

IV - intravenous; IH - inhalational

There we no data loss and all patients $(n=80)$ completed the study as per protocol and were included for analysis Figure 1 (Consolidated Standards of Reporting Trials [CONSORT] diagram). 


\section{Cureus}

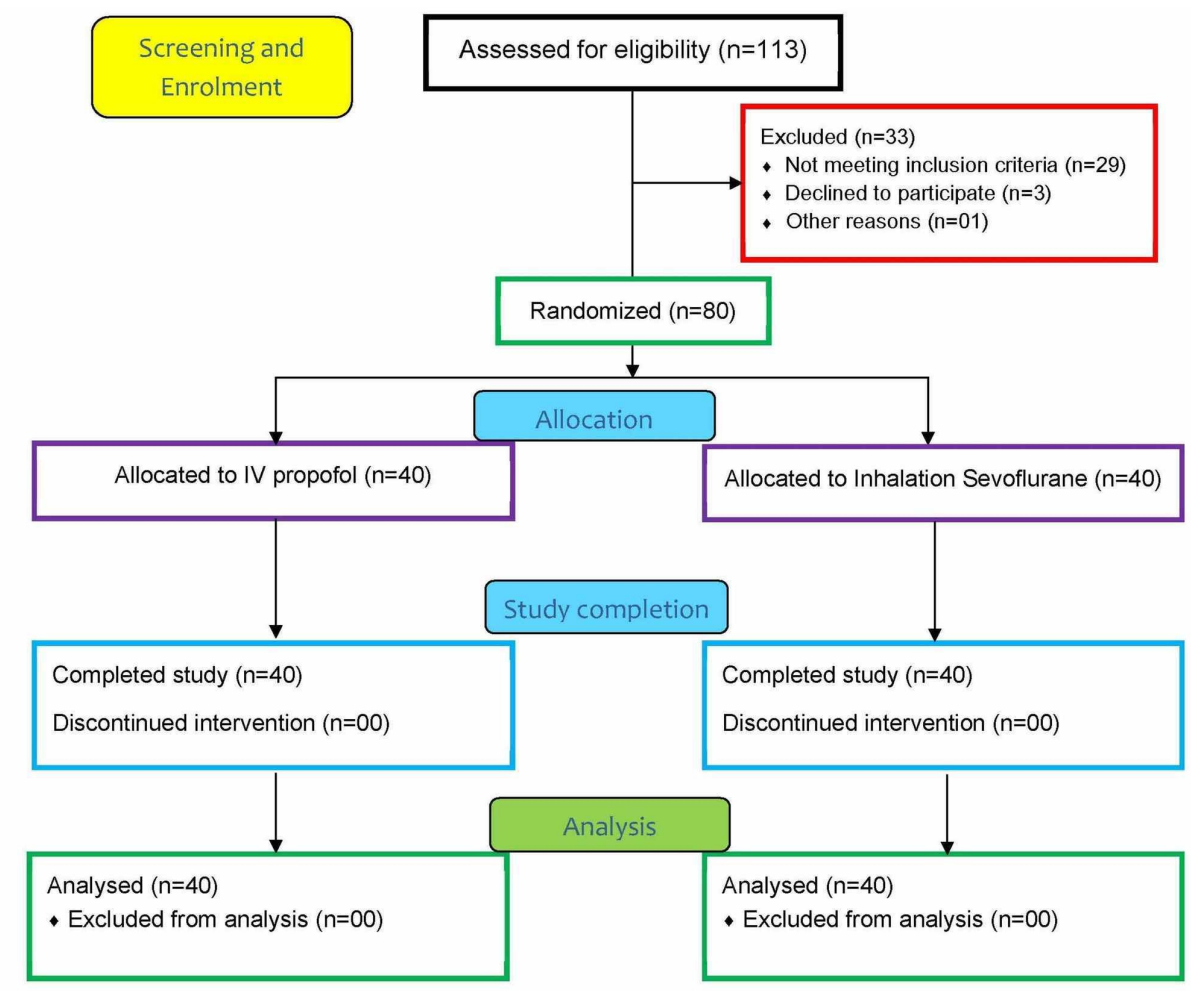

FIGURE 1: CONSORT diagram

CONSORT - Consolidated Standards of Reporting Trials

Figure 2 shows the mean heart rate (HR) at baseline and different time-points. There is a reduction in HR with sevoflurane, whereas an increase in HR with propofol after induction - this trend continues up to five minutes after intubation.

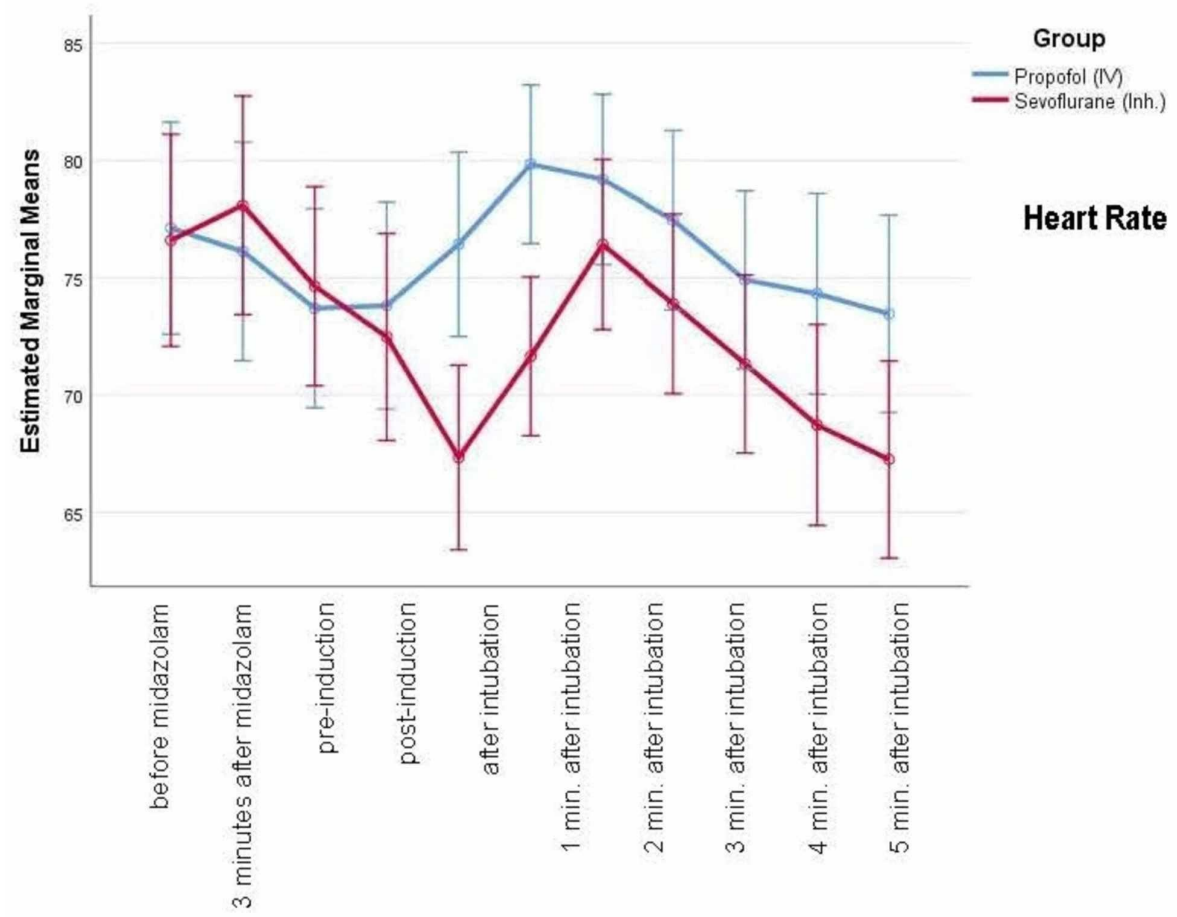

FIGURE 2: Heart rate at baseline and different time-points 


\section{Cureus}

Figure 3 shows the mean systolic blood pressure (SBP) at baseline and different time-points. There is a greater reduction in SBP with propofol compared to sevoflurane, and this reduction starts immediately after induction and continues to be low up to five minutes after intubation.

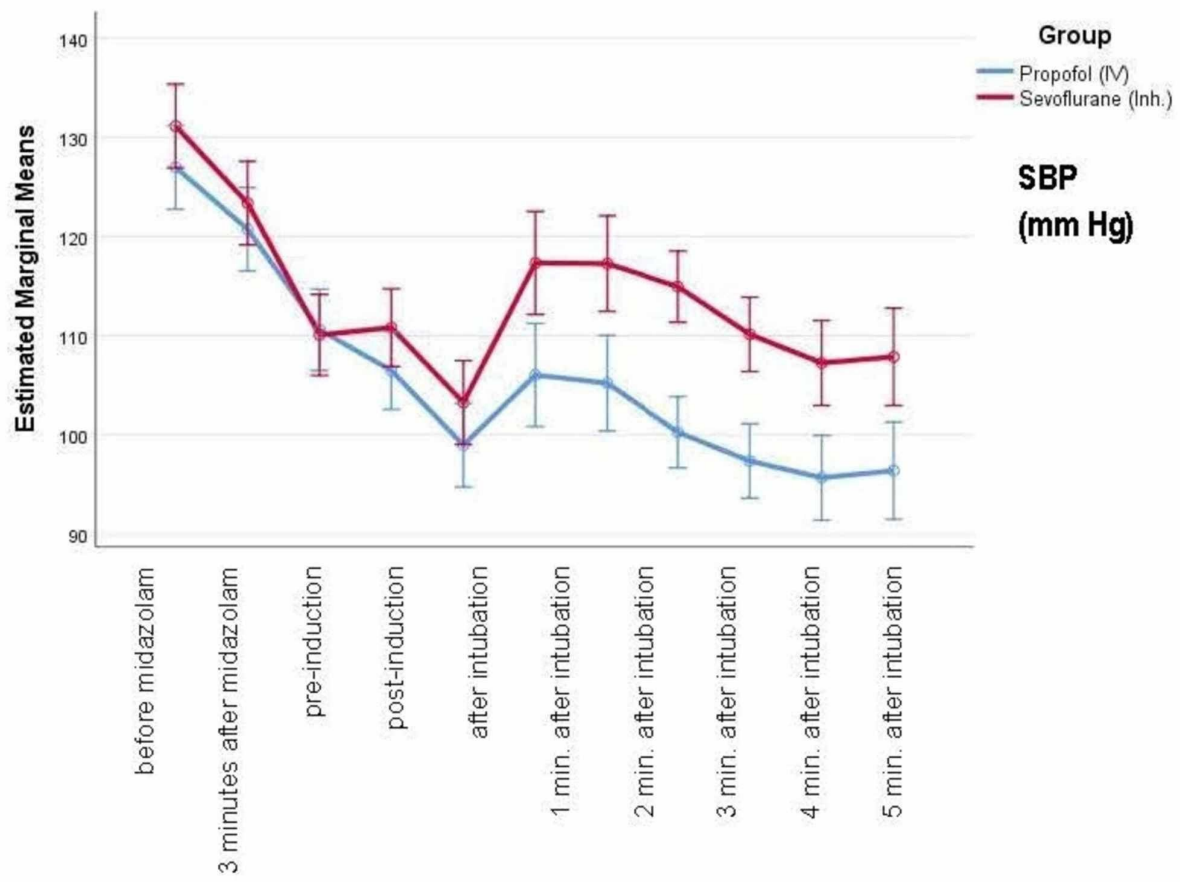

FIGURE 3: Mean SBP at baseline and different time-points

SBP - systolic blood pressure

Figure 4 shows the mean diastolic blood pressure (DBP) at baseline and different time-points. There is a greater reduction in DBP with propofol compared to sevoflurane, and this reduction starts immediately after induction and continues to be low up to five minutes after intubation. 


\section{Cureus}

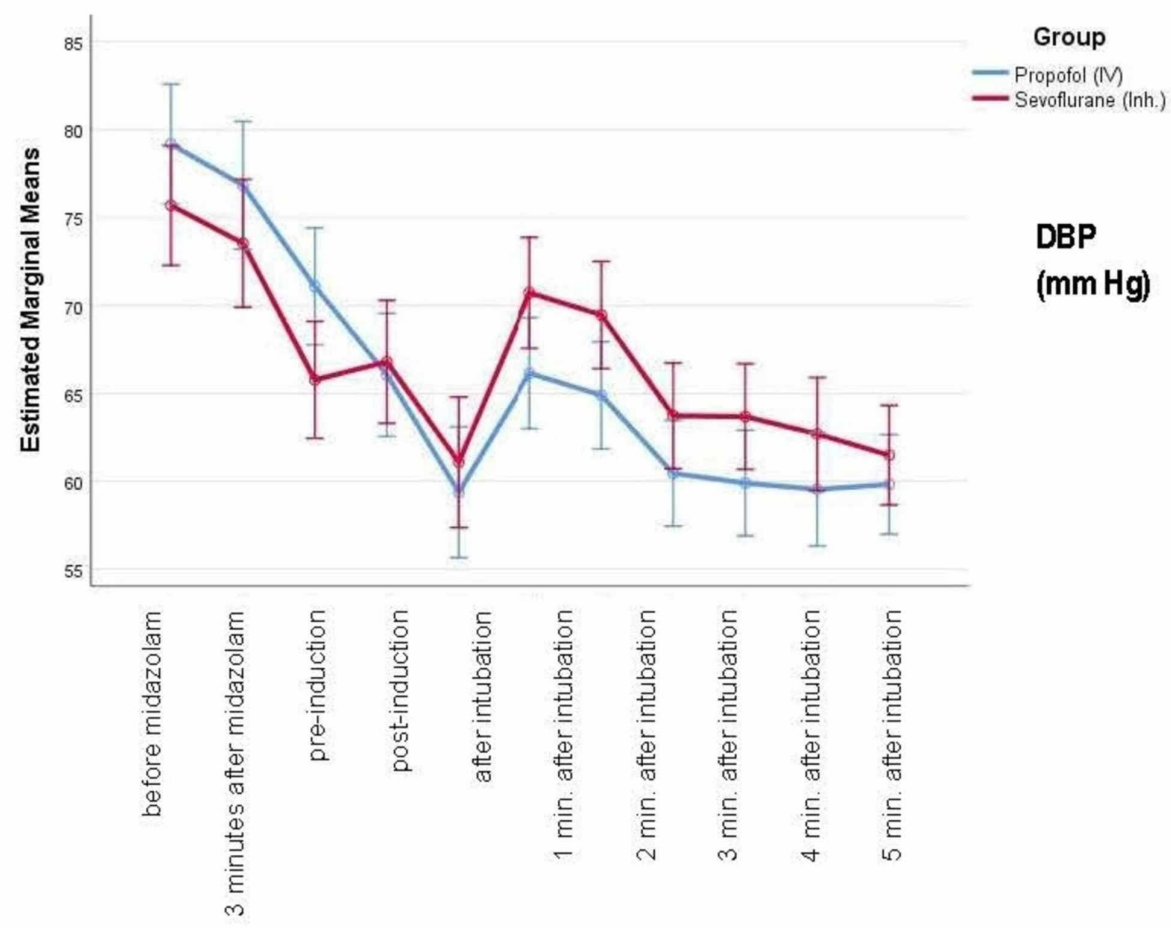

FIGURE 4: Mean DBP at baseline and different time-points DBP - diastolic blood pressure

Figure 5 shows the mean arterial pressure (MAP) at baseline and different time-points. There is a greater reduction in MAP with propofol compared to sevoflurane, and this reduction starts immediately after induction and continues to be low up to five minutes after intubation.

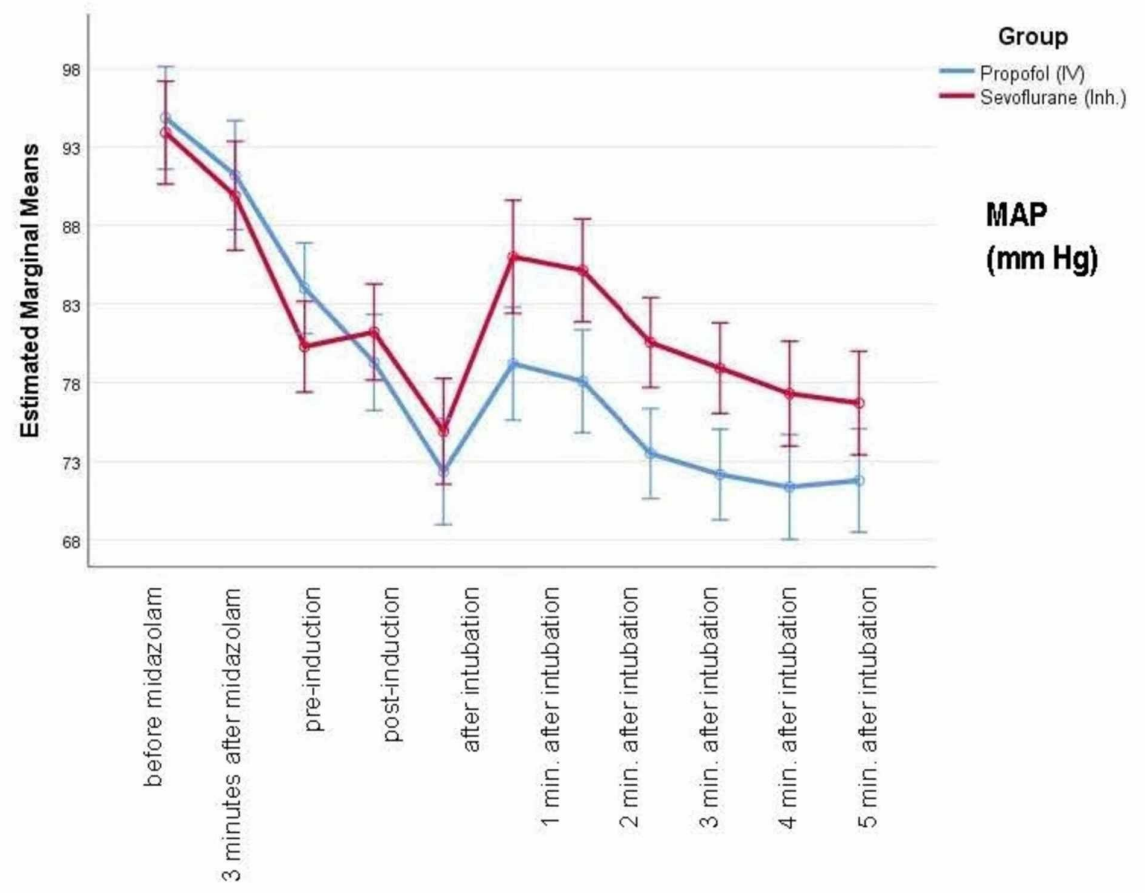

FIGURE 5: Mean MAP at baseline and different time-points

MAP - mean arterial pressure 


\section{Cureus}

Figure 6 shows the percentage change in MAP from baseline after induction. There was a greater reduction in MAP after induction with propofol compared to sevoflurane. However, the differences were not significant ( $\mathrm{p}>0.05)$.

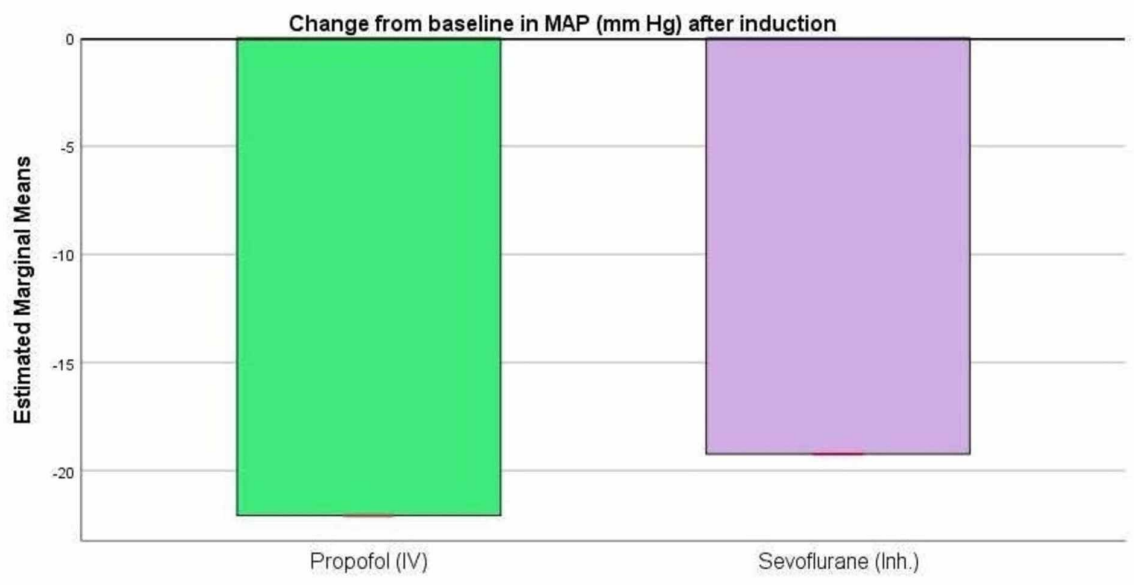

Error bars: $95 \% \mathrm{Cl}$

FIGURE 6: Percentage change in MAP from baseline after induction

MAP - mean arterial pressure

Table 2 shows the estimated means for the hemodynamic parameters for pooled data at different time points. The pooled mean estimates of MAP with sevoflurane was 82.52 and with propofol was 79.14

$(\mathrm{p}=0.028$, significant) which suggests a greater stabilization of MAP with sevoflurane. However, the effect size was very small (0.063), which probably could be due to the inadequate power of the study. The pooled mean estimates for HR were similar in the two groups ( $\mathrm{p}=0.173$ ). 


\section{Cureus}

\begin{tabular}{|c|c|c|c|c|c|c|c|c|}
\hline & Inducing agent & Mean & SE & $\begin{array}{l}95 \% \mathrm{Cl} \text { for } \\
\text { mean }\end{array}$ & $\begin{array}{l}\text { Mean } \\
\text { difference }\end{array}$ & $\mathbf{p}^{*}$ & $\begin{array}{l}\text { Effect } \\
\text { size }\end{array}$ & Power \\
\hline \multirow[b]{2}{*}{ Heart rate (per min.) } & Propofol (IV) & 76.04 & 1.75 & (72.54 - 79.53) & \multirow[b]{2}{*}{3.451} & \multirow{2}{*}{0.173} & \multirow[b]{2}{*}{0.025} & \multirow[b]{2}{*}{0.274} \\
\hline & $\begin{array}{l}\text { Sevoflurane } \\
\text { (IH) }\end{array}$ & 72.59 & 1.75 & (69.09-76.08) & & & & \\
\hline \multirow{2}{*}{ Systolic blood pressure (mm Hg) } & Propofol (IV) & 105.93 & 1.55 & $\begin{array}{l}(102.83- \\
109.02)\end{array}$ & \multirow{2}{*}{-8.059} & \multirow{2}{*}{0.001} & \multirow{2}{*}{0.150} & \multirow{2}{*}{0.948} \\
\hline & $\begin{array}{l}\text { Sevoflurane } \\
\text { (IH) }\end{array}$ & 113.99 & 1.55 & $\begin{array}{l}(110.89- \\
117.08)\end{array}$ & & & & \\
\hline \multirow{2}{*}{$\begin{array}{l}\text { Diastolic blood pressure (mm } \\
\mathrm{Hg})\end{array}$} & Propofol (IV) & 65.75 & 1.02 & $(63.73-67.78)$ & \multirow[b]{2}{*}{-1.030} & \multirow{2}{*}{0.480} & \multirow{2}{*}{0.007} & \multirow{2}{*}{0.108} \\
\hline & $\begin{array}{l}\text { Sevoflurane } \\
\text { (IH) }\end{array}$ & 66.78 & 1.02 & $(64.76-68.81)$ & & & & \\
\hline \multirow[b]{2}{*}{ Mean arterial pressure $(\mathrm{mm} \mathrm{Hg})$} & Propofol (IV) & 79.14 & 1.05 & $(77.04-81.25)$ & \multirow[b]{2}{*}{-3.373} & \multirow{2}{*}{0.028} & \multirow[b]{2}{*}{0.063} & \multirow[b]{2}{*}{0.599} \\
\hline & $\begin{array}{l}\text { Sevoflurane } \\
\text { (IH) }\end{array}$ & 82.52 & 1.05 & $(80.42-84.62)$ & & & & \\
\hline
\end{tabular}

TABLE 2: Estimated means for hemodynamic parameters (pooled)

* Repeat measures analysis of covariance (ANCOVA) with covariates evaluated at the following values: Age (years) $=33.88$, Gender $=1.39$, Body weight $=60.03$.

IV - intravenous; IH - inhalational; ANCOVA - analysis of covariance; $\mathrm{Cl}$ - confidence interval

Table 3 shows the descriptives for percent change in hemodynamic parameters from baseline to postinduction in the two groups. There was a reduction in heart rate with sevoflurane by $9.71 \%$ after induction as against propofol, which had no effect on HR after induction. There were greater but not significant reductions ( $\mathrm{p}>0.05$ ) in SBP, DBP, and MAP with propofol as compared to sevoflurane.

\begin{tabular}{|c|c|c|c|c|c|c|}
\hline & \multicolumn{2}{|c|}{ IV propofol $(n=40)$} & \multicolumn{2}{|c|}{ IH sevoflurane $(n=40)$} & \multicolumn{2}{|c|}{ ANOVA } \\
\hline & Mean & SD & Mean & SD & $\mathrm{F}$ & $\mathrm{p}$ \\
\hline Heart rate (per min.) & -0.70 & 15.89 & -9.71 & 13.05 & 7.647 & 0.007 \\
\hline Systolic blood pressure (mm Hg) & -21.87 & 8.60 & -20.93 & 9.09 & 0.222 & 0.639 \\
\hline Diastolic blood pressure (mm Hg) & -25.16 & 19.59 & -16.76 & 19.17 & 3.759 & 0.056 \\
\hline Mean arterial pressure $(\mathrm{mm} \mathrm{Hg})$ & -23.93 & 12.90 & -19.23 & 10.08 & 3.293 & 0.073 \\
\hline
\end{tabular}

\section{TABLE 3: Percent change in hemodynamic parameters from baseline to post-induction}

IV - intravenous; IH - inhalational; SD - standard deviation; ANOVA - analysis of variance

Table 4 shows the response for acceptance by patients in the two groups. Although sevoflurane was associated with unpleasant smell (5.0\%) and feeling (12.5\%), 10.0\% of patients with propofol reported pain on injection ( $\mathrm{p}=0.041$, significant). The proportion of patients who reported the induction procedure unpleasant was similar ( $\mathrm{p}=0.326$, not significant) with sevoflurane $(12.5 \%)$ and propofol $(10.0 \%)$. A total of 36 (90.0\%) patients reported they would prefer propofol for a repeat procedure, whereas with sevoflurane 34 (85.0\%) patients reported the same ( $\mathrm{p}=0.202$, not significant). 


\section{Cureus}

\begin{tabular}{|c|c|c|c|c|c|c|}
\hline & \multicolumn{2}{|c|}{ IV propotol ( $(=40)$} & \multicolumn{2}{|c|}{ IH sevoflurane $(n=40)$} & \multicolumn{2}{|c|}{ Chl-square test } \\
\hline & No. & $\%$ & No. & $\%$ & Chi-square & $p$ \\
\hline \multicolumn{7}{|c|}{ Opinion on induction procedure } \\
\hline Mask unpleasant & 0 & - & 5 & $12.5 \%$ & 5.267 & 0.022 \\
\hline Smell unpleasant & 0 & - & 2 & $5.0 \%$ & 2.026 & 0.157 \\
\hline Pain on injection & 4 & $10.0 \%$ & 0 & - & 4.158 & 0.041 \\
\hline \multicolumn{7}{|c|}{ Upinion on anestnetic } \\
\hline Pleasant & 36 & $90.0 \%$ & 33 & $82.5 \%$ & \multirow{3}{*}{2.242} & \multirow{3}{*}{0.326} \\
\hline Indifferent & 0 & - & 2 & $5.0 \%$ & & \\
\hline Unpleasant & 4 & $10.0 \%$ & 5 & $12.5 \%$ & & \\
\hline \multicolumn{7}{|c|}{ Choice of anesthetic for similar procedure in the future } \\
\hline Same & 36 & $90.0 \%$ & 34 & $85.0 \%$ & \multirow{3}{*}{3.200} & \multirow{3}{*}{0.202} \\
\hline Different & 0 & - & 3 & $7.5 \%$ & & \\
\hline No preference & 4 & $10.0^{\circ}$ & 3 & $7.5 \%$ & & \\
\hline
\end{tabular}

\section{TABLE 4: Acceptance by patients in the two groups}

IV - intravenous; IH - inhalational

Figure 7 shows the mean cost (INR) for the induction of anesthesia. The per-unit cost of propofol is higher than that for sevoflurane when used for induction of anesthesia.

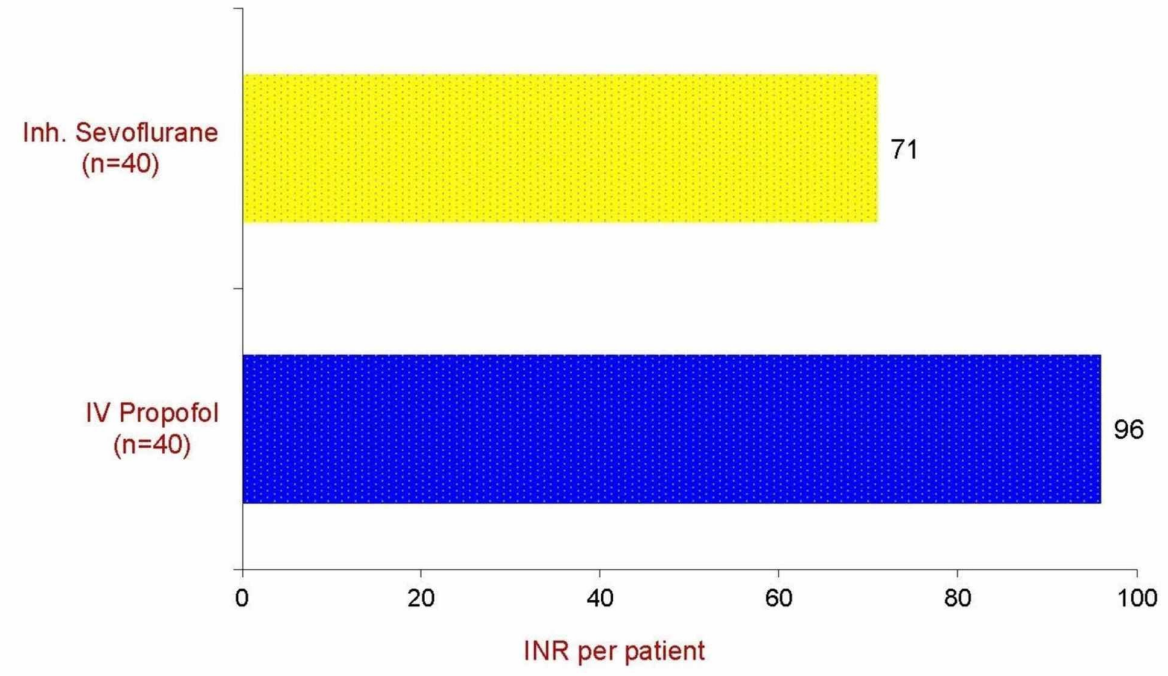

\section{FIGURE 7: Mean cost (INR) for induction of anesthesia}

INR - Indian rupee; IV - intravenous; Inh. - inhalational

\section{Discussion}

The choice of anesthetic could be different for patients with different ages and their underlying conditions [9]. Hemodynamic changes occurring during surgical anesthesia is a great cause of concern for both surgeons and anesthetists since it may be associated with various complications [10]. Techniques and methods used in the induction of anesthesia are designed to minimize hemodynamic instability, especially 
in geriatric patients [11].

Sevoflurane is an inhalational anesthetic drug having the least undesirable effects on hemodynamic changes and could be a better alternative to IV propofol, especially in patients prone to cardiovascular derangement. Propofol is a widely accepted induction agent and is favored for its early and "clear-headed" recovery facilitating early discharge. However, its potent depressing effects on the cardiovascular system, especially in combination with opioids, are little. Hence, due to its ability to reduce mean arterial pressure, propofol is being used along with ketamine or etomidate to reduce its effect on hemodynamic instability [12]. With the introduction of inhalational sevoflurane in anesthesia practice, a new era in the induction of anesthesia has begun due to its ability to smooth induction and early awakening [8, 13]. Although studies have demonstrated a favorable profile of sevoflurane over propofol as an inducing, maintenance, and recovery agent for outpatient anesthesia, there are limited studies on its effect on hemodynamic stability [14]. In this prospective, randomized comparative clinical study, we compared the effects of inhalational sevoflurane and IV propofol used for the induction of general anesthesia in adult patients. We observed that there was a significant decrease in the SBP, DBP, and MAP with propofol and not with sevoflurane after induction and up to five minutes after intubation. Although heart rate was increased with propofol and decreased marginally with sevoflurane, it may not be detrimental to cardiovascular stability. However, we observed that with sevoflurane, intubation led to a greater rise in heart rate, which continued for one minute and then slowly came down. With propofol, the raised heart rate after intubation almost immediately started falling but remained higher than the sevoflurane group at each corresponding time intervals. This pattern with propofol could be due to the resetting of baroreceptors, inhibition of sympathetic activity, and increased venous capacities. The rise in MAP due to intubation was similar in both groups, whereas, at five minutes after intubation, the fall in MAP with propofol was greater compared to sevoflurane $(\mathrm{p}<0.05)$. These results are indicative of better hemodynamic stability after induction with inhalational sevoflurane. Sevoflurane has attributes that facilitate rapid, smooth inhaled induction, has low blood gas solubility, the relative absence of pungency, and a vaporizer with high overpressure capability [15, 16]. The non-pungent odor of sevoflurane improves its acceptance for inhalation for most patients [17]. Our results suggest that sevoflurane is hemodynamically more stable and cost-effective than propofol and can be used as an induction technique in adult patients. Frink et al. also have drawn similar conclusions in their comparative study [18].

Patient acceptance is an important criterion for the selection of an inducing agent. We assessed the acceptance of anesthesia induction from the patient's perspective and found it comparable in the two groups. About $90 \%$ of patients in the propofol group and $85 \%$ in sevoflurane groups were willing to receive the same anesthetic in the future. These findings agree with those by Sloan et al., who reported that sevoflurane odor to be pleasant, and it was popular among almost all patients [19]. However, Thaiwaiteset al. reported that patients described the smell of sevoflurane as unpleasant [8]. The introduction of newer inhalational agents has led to several pharmacoeconomic comparative studies to determine the relative cost. Factors that must be considered when studying the cost of these new volatile agents include high acquisition costs, although the use of a low fresh gas flow circle system may reduce the amount of this agent used. This, in turn, may have cost implications in those situations where rapid recovery has financial implications. To date, the available pharmacoeconomic data concerning propofol in day-case surgery consider only acquisition cost or per-minute administration costs of the drug. However, in considering only drug acquisition costs, these studies fail to evaluate other costs and benefits involved in anesthesia; various costs that should be considered for a complete economic evaluation of propofol include equipment, the cost of treating drug-related adverse effects, and staff salaries. The whole issue of whether anesthetic agents with rapid recovery profiles actually do decrease costs through an effect on recovery room stay is unclear. Similarly, Eger et al. reported that desflurane might be used in low flow circle systems with cost advantages, but it may be undesirable in the case of sevoflurane, due to its reaction with soda lime [20]. The cost of an inhaled anesthetic is not as simple to determine as that of an intravenous drug. The amount of inhaled anesthetic used can be calculated based on the anesthetic drug concentration and fresh gas flow, and this method has been used previously to assess the cost of induction of sevoflurane anesthesia [8]. In practice, the cost of intravenous induction depends on how much induction agent is actually drawn up and whether the remaining ampoule is discarded. We calculated the cost of propofol on the basis of the exact amount (ml) of propofol required. We observed that the induction of anesthesia with sevoflurane was significantly less costly compared with propofol.

The findings of our study are limited in terms of its generalizability due to the small sample size. The effect size and the power achieved with the analysis for the primary outcome were very limited, and further studies are warranted.

\section{Conclusions}

Sevoflurane seems to have a better hemodynamic stability after induction compared to IV propofol. The patient acceptance is similar with the two inducing agents, but inhalational sevoflurane is more cost effective than IV propofol. However, further studies with large sample are required to substantiate these effects.

\section{Additional Information}




\section{Disclosures}

Human subjects: Consent was obtained by all participants in this study. IEC, Deenanath Mangeshkar Hospital and Research Center, Pune issued approval PR/ANAE/C/58/06. The study protocol and the related documents were reviewed and approved by the IEC. Animal subjects: All authors have confirmed that this study did not involve animal subjects or tissue. Conflicts of interest: In compliance with the ICMJE uniform disclosure form, all authors declare the following: Payment/services info: All authors have declared that no financial support was received from any organization for the submitted work. Financial relationships: All authors have declared that they have no financial relationships at present or within the previous three years with any organizations that might have an interest in the submitted work. Other relationships: All authors have declared that there are no other relationships or activities that could appear to have influenced the submitted work.

\section{Acknowledgements}

The authors acknowledge Dr. Ramchandra Lahande and Dr. Sachin Ghodki for their support during the conduct of this work.

\section{References}

1. Fredman B, Nathanson MH, Smith I, Wang J, Klein K, White PF: Sevoflurane for outpatient anesthesia: a comparison with propofol. Anesth Analg. 1995, 81:823-828.

2. Brown GW, Patel N, Ellis FR: Comparison of propofol and thiopentone for laryngeal mask insertion. Anaesthesia. 1991, 46:771-772. 10.1111/j.1365-2044.1991.tb09776.x

3. Jellish WS, Lien CA, Fontenot HJ, Hall R: The comparative effects of sevoflurane versus propofol in the induction and maintenance of anesthesia in adult patients. Anesth Analg. 1996, 82:479-485. 10.1097/00000539-199603000-00009

4. Black A, Sury MR, Hemington L, Howard R, Mackersie A, Hatch DI: A comparison of the induction characteristics of sevoflurane and halothane in children. Anaesthesia. 1996, 51:539-542. 10.1111/j.13652044.1996.tb12559.x

5. Raeder J, Gupta A, Pedersen FM: Recovery characteristics of sevoflurane -or propofol-based anesthesia for day-care surgery. Acta Anaesthesiol Scand. 1997, 41:988-994. 10.1111/j.1399-6576.1997.tb04825.x

6. Venkateswaran V, Jain AK, Verma UC: Cost analysis of three techniques of administering sevoflurane . Anes Res Pract. 2014, 2014:1-6. 10.1155/2014/459432

7. Haris RS, Lazar O, Johansen J, Sebel PS: Interaction of propofol and sevoflurane on loss of consciousness and movement to skin incision during general anesthesia. Anesthesiology. 2006, 104:1170-1175. 10.1097/00000542-200606000-00011

8. Thwaites AJ, Edmends S, Smith I: Inhalation induction with sevoflurane: a double-blind comparison with propofol. Brit J of Anesth. 1997, 78:356-361. 10.1093/bja/78.4.356

9. Hou JF, Xiao CL: Effect of propofol and sevoflurane anesthesia on postoperative cognitive function and levels of A $\beta-42$ and Tau in patients undergoing hepatectomy. Eur Rev Med Pharmacol Sci. 2019, 23:849856. 10.26355/eurrev_201901_16900

10. Felfernig M, Andel D, Weintraud M, Connor D, Andel H, Blaicher AM: Postoperative vigilance in patients with total intravenous anaesthesia with ketamine/propofol. J R Nav Med Serv. 2006, 92:64-68.

11. Passot S, Servin F, Pascal J, Charret F, Auboyer C, Molliex S: A comparison of target- and manually controlled infusion propofol and etomidate/desflurane anesthesia in elderly patients undergoing hip fracture surgery. Anesth Analg. 2005, 100:1338-1342. 10.1213/01.ANE.0000149542.04833.55

12. Hosseinzadeh H, Eidy M, Golzari S, Vasebi M: Hemodynamic stability during induction of anesthesia in elderly patients: propofol + ketamine versus propofol + etomidate. J Cardiovasc Thorac Res. 2013, 5:51-54.

13. Mashour GA: Consciousness unbound, towards a paradigm of general anesthesia . Anesthesiology. 2004, 100:428-433. 10.1097/00000542-200402000-00035

14. Hall JE, Oldham TA, Stewart JI, Harmer M: Comparison between halothane and sevoflurane for adult vital capacity induction. Brit J of Anesth. 1997, 79:285-288. 10.1093/bja/79.3.285

15. Philip BK, Lombard LL, Roaf ER, Drager LR, Calalang I, Philip JH: Comparison of vital capacity induction with sevoflurane to intravenous induction with propofol for adult ambulatory anesthesia. Anesth Analg. 1999, 89:623-627. 10.1097/00000539-199909000-00014

16. Nobuhiko Y, Lockhart S, Eger E et al.: Comparison of kinetics of sevoflurane and isoflurane in humans . Anesth Analg. 1991, 72:316-324. 10.1213/00000539-199103000-00007

17. Meyer T, Pharm D: Clinical and economic considerations in the use of inhaled anesthesia from the perspective of health-system pharmacists and anesthesiologists Introduction. Am J Health Syst Pharm. 2010, 67:S2-S3. 10.2146/ajhp100091

18. Frink EJ Jr, Malan TP, Atlas M, Dominguez LM, DiNardo JA, Brown BR: Clinical comparison of sevoflurane and isoflurane in healthy patients. Anesth Analg. 1992, 74:241-245. 10.1213/00000539-199202000-00012

19. Sloan MH, Conard PF, Karsunky PK, Gross JB: Sevoflurane versus isoflurane: induction and recovery characteristics with single - breath inhaled induction of anesthesia. Anesth Analg. 1996, 82:528-532. 10.1097/00000539-199603000-00018

20. Eger EI: Economic analysis and pharmaceutical policy: a consideration of the economics of the use of desflurane. Anesthesia. 1995, 50:45-48. 10.1111/j.1365-2044.1995.tb06190.x 